\title{
Can we increase efficiency of CT lung cancer screening by combining with CVD and COPD screening? Results of an early economic evaluation
}

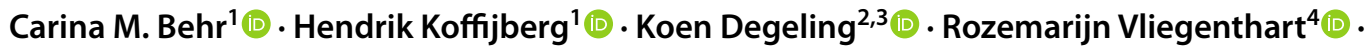 \\ Maarten J. IJzerman ${ }^{1,2,3}$ (1)
}

Received: 12 August 2021 / Revised: 13 October 2021 / Accepted: 18 October 2021 / Published online: 1 January 2022

(c) The Author(s) 2021

\begin{abstract}
Objectives Estimating the maximum acceptable cost (MAC) per screened individual for low-dose computed tomography (LDCT) lung cancer (LC) screening, and determining the effect of additionally screening for chronic obstructive pulmonary disease (COPD), cardiovascular disease (CVD), or both on the MAC.

Methods A model-based early health technology assessment (HTA) was conducted to estimate whether a new intervention could be cost-effective by calculating the MAC at a willingness-to-pay (WTP) of €20k/quality-adjusted life-year (QALY) and $€ 80 \mathrm{k} / \mathrm{QALY}$, for a population of current and former smokers, aged 50-75 years in The Netherlands. The MAC was estimated based on incremental QALYs gained from a stage shift assuming screened individuals are detected in earlier disease stages. Data were obtained from literature and publicly available statistics and validated with experts.

Results The MAC per individual for implementing LC screening at a WTP of €20k/QALY was $€ 113$. If COPD, CVD, or both were included in screening, the MAC increased to $€ 230, € 895$, or $€ 971$ respectively. Scenario analyses assessed whether screening-specific disease high-risk populations would improve cost-effectiveness, showing that high-risk CVD populations were more likely to improve economic viability compared to COPD.

Conclusions The economic viability of combined screening is substantially larger than for LC screening alone, primarily due to benefits from CVD screening, and is dependent on the target screening population, which is key to optimise the screening program. The total cost of breast and cervical cancer screening is lower (€420) than the MAC of Big-3, indicating that Big-3 screening may be acceptable from a health economic perspective.

Key Points

- Once-off combined low-dose CT screening for lung cancer, COPD, and CVD in individuals aged 50-75 years is potentially cost-effective if screening would cost less than $€ 971$ per screened individual.

- Multi-disease screening requires detailed insight into the co-occurrence of these diseases to identify the optimal target screening population.

- With the same target screening population and WTP, lung cancer-only screening should cost less than $€ 113$ per screened individual to be cost-effective.
\end{abstract}

Keywords Cost-benefit analysis · Mass screening · Lung neoplasms · Pulmonary disease, chronic obstructive · Cardiovascular diseases

Maarten J. IJzerman

maarten.ijzerman@unimelb.edu.au

1 Health Technology and Services Research, Faculty of Behavioural and Management Science, University of Twente, Drienerlolaan 5, 7522 NB Enschede, The Netherlands

2 Cancer Health Services Research, University of Melbourne Centre for Cancer Research, Faculty of Medicine, Dentistry and Health Sciences, The University of Melbourne, Parkville, Melbourne VIC 3010, Australia
3 Cancer Health Services Research, Centre for Health Policy, Melbourne School of Population and Global Health, Faculty of Medicine, Dentistry and Health Sciences, The University of Melbourne, Parkville, Melbourne VIC 3010, Australia

4 Dept of Radiology, University of Groningen, University Medical Centre Groningen, Hanzeplein 1, 9713 GZ Groningen, The Netherlands 


$\begin{array}{ll}\text { Abbreviations } \\ \text { COPD } & \text { Chronic obstructive pulmonary disease } \\ \text { CVD } & \text { Cardiovascular disease } \\ \text { LC } & \text { Lung cancer } \\ \text { LDCT } & \text { Low-dose CT } \\ \text { QALY } & \text { Quality-adjusted life-year } \\ \text { WTP } & \text { Willingness-to-pay }\end{array}$

\section{Introduction}

In The Netherlands, lung cancer (LC) accounts for over 13,000 diagnoses and 10,000 deaths annually [1]. Given its high disease burden, there is interest in early detection through population-based screening using low-dose computed tomography (LDCT) to reduce LC-related mortality.

Several studies such as the largest National Lung Screening Trial (NLST) and Dutch-Belgian Randomized Lung Cancer Screening (NELSON) trial demonstrated the clinical benefits of LC screening for an at-risk population [2, 3]. Additionally, recent cost-effectiveness studies were published for different countries, including the UK [4], the USA [5], Germany [6], and Canada [7]. Although the cost-effectiveness of LC screening was generally acceptable in populations aged 50-80 years with different smoking histories, the cost-effectiveness varied from $€ 21 \mathrm{k}$ to $85 \mathrm{k}$ per life-year gained (LYG) and from $€ 30 \mathrm{k}$ to $140 \mathrm{k}$ per quality-adjusted life-year (QALY), which provides evidence that screening is cost-effective in some subgroups relative to given willingness-to-pay (WTP) thresholds [4-8].

The published cost-effectiveness studies focused on LC screening only. However, screening for additional diseases simultaneously could be economically attractive, particularly for diseases with an indolent start and shared risk factors (9). Chest LDCT, used in LC screening, can simultaneously detect early stages of chronic obstructive pulmonary disease (COPD) through emphysema or air trapping evaluation and high cardiovascular disease (CVD) risk based on coronary calcium scoring; both diseases pose a large burden on Western societies [9]. LC, COPD, and CVD together are also called the Big-3 [9].

Although the value of LDCT screening of COPD and CVD is still under debate $[10,11]$, the additional screening for these diseases within a lung cancer screening program could further improve the health outcomes of lung cancer screening at marginal additional costs as there is evidence indicating that many individuals in lung cancer screening programs have high, unrecognised CVD risks [12]. COPD and CVD are both diseases that can be detected and acted upon in the early stages. There are as yet no clinical trials with outcome results that prove the effectiveness of COPD or CVD screening with LDCT as a source of evidence. Therefore, this study is conducted as an early health technology assessment using the limited evidence available. Using this limited evidence in modelling can be beneficial to estimate if combination screening could offer an attractive alternative to screening for LC only. Health economists proposed methods using expected health benefits of combination screening, additional cost, and a certain willingness-to-pay (WTP) threshold, to estimate the maximum acceptable cost (MAC) under optimistic circumstances. If the anticipated screening cost is higher than the MAC, the program is unlikely to be cost-effective. Such analyses, called headroom analyses, have been proven useful to inform decisions on further research [13-16] and are preferred during the intervention and evidence development, to optimize further data collection and to more accurately estimate the long-term health economic impact when more clinical evidence becomes available.

This study aims to estimate the MAC per screened individual in The Netherlands for LC screening and to determine the effect of additional screening for COPD, CVD, or both.

\section{Materials and methods}

This study compared once-off LDCT screening for LC, with the addition of CVD, COPD, or both to no-screening in a stochastic data-based analysis without the involvement of participants. Although annual and biennial screening is more common, a single screening round is considered a starting point and in some cases could be more cost-effective than repeated screening [17].

The optimistic MAC for screening was calculated for two WTP thresholds based on estimated health benefits and treatment costs per disease stage. These calculations were based on population-level data for disease stage-specific health outcomes and costs. The high-risk target screening population was current and former smokers aged 50-75 in The Netherlands, corresponding to the population of the NELSON trial [18]. Details on the input values with its sources, how each disease was modelled, and the scenarios are given in the supplements.

\section{General approach}

This analysis used a stage-shift model that is relevant to progressive diseases, where screened individuals are detected in earlier disease stages than non-screened individuals [19-24]. Detection in an earlier stage increases the therapeutic window and thus health benefits. LC was classified by tumour, node, metastasis (TNM) staging [25], and COPD by the Global Initiative for Obstructive Lung Disease (GOLD) criteria [26]. Individuals at risk of CVD were grouped into three risk categories, based on risk factors, for determining the proportion of individuals per risk category experiencing CVD events [20]. The modelling 
of health effects after screening differs per disease. For LC, the most evidence exists and it can be assumed that screening results in a stage shift, where utility and costs of lower disease stages are assigned to more patients and later disease stages to fewer patients. Given the lack of evidence for the efficacy of COPD and CVD screening, the health effects are modelled as follows. For COPD, the assumed health effect is that a stage-specific proportion (0.2-0.3) [27] of diagnosed patients will stop smoking which slows progression (modelled by annual rate of decline in FEV1). The rates used here are comparable with smoking cessation found in the NELSON trial [28]. COPD patients who do not stop smoking are assumed not to have health benefits, but only COPD-related maintenance costs. Individuals at risk of CVD in the model may experience no CVD-event, experience a CVDevent with the related disutility and costs, or experience a fatal CVD-event with related costs. Due to preventative treatment of at-risk individuals, the probability that a fatal or non-fatal CVD event is experienced declines.

\section{Calculating MAC}

The MAC represents the maximum cost of LDCT and organisational costs for screening to be cost-effective. The MAC or headroom [29] was calculated according to the following formula for various WTP thresholds, where direct healthcare costs for disease management were included in the IncrementalCosts and QALYs were included in the EffectivenessGap for screening compared to no-screening:

MAC for screening $=($ EffectivenessGap $* W T P)-$ IncrementalCost

\section{Analysis and scenarios}

The analysis was conducted in $\mathrm{R}$ version 3.6.1 [30]. The MAC per screened individual was calculated for the base case with two additional scenarios to assess the impact of assumptions. Depending on the diseases screened for and the screening population considered, the utility, survival, incidence rate, and costs were adjusted. Details for the scenarios are presented in Supplement Table 3, and a high-level overview is provided in this paper.

The base-case analysis estimates the MAC based on the difference between the current stage distribution in The Netherlands with no screening (A) and a realistic stage distribution (B) after screening based on literature.

\section{Input parameters}

Inputs for the MAC calculation included incidence rates, stage distributions of patients with and without screening, and disease-stage-specific estimates of quality of life (utility), survival, and disease management costs. The disease management cost per patient over average life expectancy for each LC or COPD stage or per CVD event included direct healthcare costs, such as cost of treatment, GP and specialist visits, and hospitalisation [31-34]. The cost of implementing screening, such as invitations and data management, was not included. Figure 1 displays the decision model with the input values used for non-small cell (NSC) LC.

For purpose of illustration, Table 1 demonstrates how the MAC can be calculated for screening for NSCLC only. Similar calculations were performed for SCLC, COPD, and CVD. The incidence rate, utility, survival, and stage distribution (with or without screening) were used to calculate the EffectivenessGap. These same inputs and the stage-specific disease management costs were used to calculate the IncrementalCost.
Fig. 1 Stage distributions of LC as currently observed (A), and assuming a plausible stage distribution (B) and a stage distribution with best possible screening outcomes $(\mathrm{C})$, as well as the health and economic outcomes per disease stage. Supplement-Fig. 1 presents this information for COPD and CVD as well. LC, lung cancer; COPD, chronic obstructive pulmonary disease; CVD, cardiovascular disease

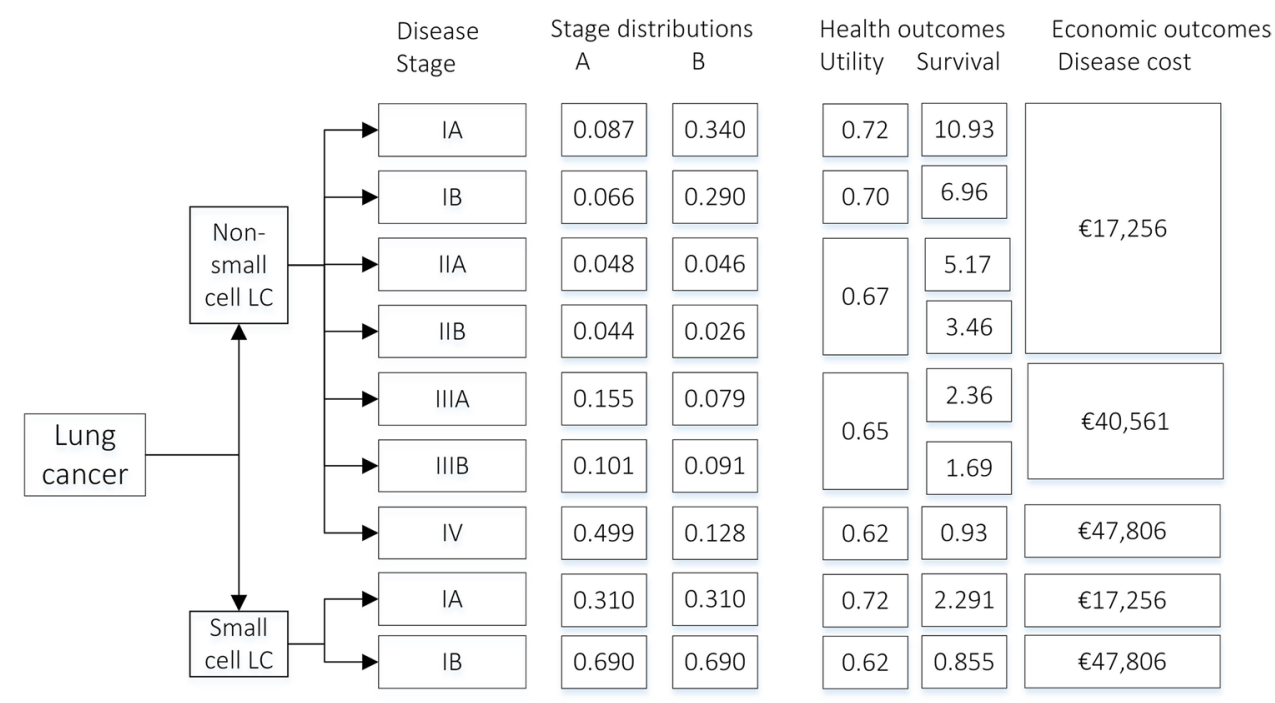


Table 1 Example of MAC calculation for non-small cell lung cancer (NSCLC) screening

\begin{tabular}{|c|c|c|c|c|c|c|}
\hline \multirow[b]{2}{*}{$\begin{array}{l}\text { Non-small } \\
\text { cell LC } \\
\text { stage }\end{array}$} & \multicolumn{2}{|c|}{$\begin{array}{l}\text { Model input: stage dis- } \\
\text { tributions reflecting the } \\
\text { effect of screening }\end{array}$} & \multicolumn{2}{|c|}{$\begin{array}{l}\text { Model input: expected quality of life (measured } \\
\text { in QALYs) and cost from diagnosis }\end{array}$} & \multirow{2}{*}{$\begin{array}{l}\text { Effect of screening } \\
\text { QALY gains from } \\
\text { screening ( Effective- } \\
\text { nessGap) }\end{array}$} & \multirow{2}{*}{$\begin{array}{l}\text { Output: MAC of screening } \\
\text { WTP* } \times \text { effectiveness } \\
\text { gap - incremental costs }\end{array}$} \\
\hline & No-screening & Screening & $\begin{array}{l}\text { QALY gains com- } \\
\text { pared to healthy } \\
\text { individuals }\end{array}$ & $\begin{array}{l}\text { Incremental cost of } \\
\text { disease screening vs } \\
\text { no-screening }\end{array}$ & & \\
\hline IA & 0.087 & 0.340 & 1.080 & $€ 4,365$ & $\begin{array}{l}(0.340- \\
0.087) \times 1.080=0.27\end{array}$ & $\begin{array}{l}0.27 \times 20,000-4,365= \\
-€ 1,099\end{array}$ \\
\hline IB & 0.055 & 0.290 & -1.680 & $€ 3,865$ & -0.38 & $-€ 11,392$ \\
\hline IIA & 0.048 & 0.046 & -2.814 & $-€ 35$ & 0.01 & $€ 147$ \\
\hline IIB & 0.044 & 0.025 & -3.953 & $-€ 311$ & 0.07 & $€ 1,734$ \\
\hline IIIA & 0.155 & 0.079 & -4.550 & $-€ 3,083$ & 0.35 & $€ 9,999$ \\
\hline IIIB & 0.101 & 0.091 & -5.005 & $-€ 406$ & 0.05 & $€ 1,407$ \\
\hline IV & 0.499 & 0.128 & -5.270 & $-€ 17,736$ & 1.96 & $€ 56,839$ \\
\hline \multicolumn{5}{|c|}{ At the population level } & $\sum \mathrm{QALY}=0.789$ & $\underset{\text { patient }}{\sum \mathrm{MAC}=€ 59,833 \text { per } \mathrm{LC}}$ \\
\hline
\end{tabular}
able cost of the screening per screened individual

*In this example, a WTP of $€ 20 \mathrm{k} / \mathrm{QALY}$ is used. In the analysis a WTP of $€ 80 \mathrm{k} / \mathrm{QALY}$ is also considered, because these two thresholds are the lowest and highest thresholds used in The Netherlands, depending on disease severity (29)

$M A C$ maximum acceptable cost, $N S C L C$ non-small cell lung cancer, $L C$ lung cancer, $Q A L Y$ quality-adjusted life-years, $W T P$ willingness-to-pay

\section{Multiple diseases}

The calculation illustrated in Table 1 for NSCLC only was extended for all considered diseases using incidence rates and by accounting for the probability of having two or three diseases simultaneously (co-occurrences). Patients with one or more Big-3 co-occurrences (e.g., NSCLC and COPD) were assumed to have the lowest QALYs (utility x survival) and the sum of the costs of the diseases that co-occur.

\section{Alternative scenario 1: different target populations}

The MAC may change substantially when screening is implemented in different risk groups determined by age and smoking history. More detailed pieces of evidence of diagnosis within current and former smokers for specific ages are not available; therefore, the MAC was also calculated for two easily identifiable alternative high-risk groups of the Big-3 to indicate what the effect on cost-effectiveness could be and within what range the MAC could be. Firstly, current smokers aged 50-75 and secondly, all individuals in The Netherlands over 60 years old.

\section{Alternative scenario 2: incidence rate ranges}

The base-case calculations were made using a population at risk of LC. This is logical when considering the expansion of LC screening, but might not be the most cost-effective approach for combination screening. CVD and COPD have risk factors similar to those of $\mathrm{LC}$ and thus, a population at increased LC risk will also have increased CVD and COPD risk. However, focusing first on CVD (or COPD) risk rather than LC risk would likely yield a target population with even higher CVD (or COPD) risk, but with much lower LC risk. The impact of such selection was illustrated in a scenario analysis by calculating the MAC for multiple combinations of Big-3 incidence rates. The following maximum incidence rates were chosen based on the highest reported incidence rates in subgroups found in literature: 5\% for LC, based on 2.6\% reported from the NELSON trial [35]; $40 \%$ for CVD, based on $31.6 \%$ of individuals older than 40 in urban areas with a high risk of CVD [36]; and 25\% for COPD, based on 23\% COPD incidence found in individuals over 40 years of age [37].

\section{Results}

\section{Base-case}

Table 2 presents the results for a screening population of current and former smokers between 50 and 75 years of age in The Netherlands, corresponding to approximately 3.5 million individuals $[38,39]$. Screening for all Big-3 diseases simultaneously had the largest MAC ( $€ 971$ to $€ 3,844$ ) per screened individual, depending on the WTP threshold. The MAC for Big-3 screening was substantially larger than screening for LC only which was $€ 113$ to $€ 341$, depending on the WTP. Note that the incremental disease management 
costs (or savings) are reported per screened individual, while these costs were only incurred for patients with a disease. A negative value indicates an overall cost-saving and a positive value, costs incurred. These values were driven by the cost per disease stage, which was not necessarily lower in an earlier disease stage; for example, the most expensive stage of NSCLC was stage II (Fig. 1).

These results show that screening for $\mathrm{LC}$ and CVD has a larger MAC than LC and COPD screening ( $€ 895$ compared to $€ 230$ with a low WTP). The MAC of combined screening was not merely the sum of the MAC of screening for the three diseases separately because there is an overlap of patients with co-occurrences in each group of patients with the disease.

\section{Scenario analysis: impact of changing the target population}

Table 3 shows the impact of targeting screening at current smokers aged 50 to 75 in The Netherlands (approximately 1.2 million individuals). In this population, the MAC is lower than in the base case for Big-3 screening for both WTP (e.g. $€ 767$ vs $€ 971$ for a WTP of $€ 20 \mathrm{k} / \mathrm{QALY}$ ). For LConly screening, the MAC is higher in a smoking population than in the base case (€340 vs $€ 113$ ). The smoking population included a smaller number of patients and a proportion of patients with at least one disease than the base-case population while the relative disease incidence rates did not change substantially compared to the base-case population. This means that the incremental health benefits only applied to a small subgroup and therefore the MAC per screened individual was smaller.
Table 4 shows the impact of targeting screening at a population of all individuals over the age of 60 (4.5 million individuals). In this older population, the larger number of patients and proportion of patients with a disease $(220,366)$ compared to the base case $(155,966)$ resulted in a larger MAC ( $€ 1,082$ vs $€ 971$ for a WTP of $€ 20 \mathrm{k} / \mathrm{Q} A L Y)$.

The results in Table 3 and Table 4 suggest that, when screening for the Big-3 in a population of current smokers, or individuals over 60 years of age, the latter resulted in higher health benefits $(0.055$ vs 0.034$)$ and is, therefore, more likely to result in a cost-effective screening program.

\section{Scenario analysis: impact of changes in incidence rates}

The MAC was calculated for a range of LC incidence rates, in combination with a range of COPD incidence rates with CVD set to a maximum expected incidence rate, and separately, a range of CVD incidence rates with COPD set at a maximum expected incidence rate.

The model was used to estimate the MAC for all combinations of incidence rates for two diseases at a time and indicates that the MAC increases with increasing incidence rates (Fig. 2). The MAC increased as incidences increased, with the highest MAC achieved when the incidences for all three diseases were at their maximum plausible values (top right corner of both figures), indicating the maximal benefit of screening for a population with a high incidence rate for all three diseases, with increasing likelihood of the screening being cost-effective.

Table 2 Headroom analysis outcomes for a screening population of current and former smokers between 50 and 75 years old

\begin{tabular}{|c|c|c|c|c|c|}
\hline & & \multirow[b]{2}{*}{$\begin{array}{l}\text { Incremental disease management } \\
\text { costs ( } € \text { per screened individual) }\end{array}$} & \multirow[b]{2}{*}{$\begin{array}{l}\text { Effectiveness gap (incremental } \\
\text { QALY per screened individual) }\end{array}$} & \multicolumn{2}{|c|}{$\begin{array}{l}\text { Incremental MAC ( } € \text { per } \\
\text { screened individual) }\end{array}$} \\
\hline & & & & $\begin{array}{l}\text { WTP: } € 20 \mathrm{k} / \\
\text { QALY }\end{array}$ & $\begin{array}{l}\text { WTP: } \\
€ 80 \mathrm{k} / \\
\text { QALY }\end{array}$ \\
\hline Diseases screened* & $\begin{array}{l}\text { Patients with } \\
\text { disease }\end{array}$ & & & & \\
\hline $\mathrm{LC}+\mathrm{CVD}+\mathrm{COPD}$ & 155,966 & -14 & 0.048 & 971 & 3,844 \\
\hline $\mathrm{LC}+\mathrm{CVD}$ & 136,752 & -12 & 0.044 & 895 & 3,546 \\
\hline $\mathrm{LC}+\mathrm{COPD}$ & 43,666 & -37 & 0.009 & 230 & 809 \\
\hline LC & 13,262 & -37 & 0.004 & 113 & 341 \\
\hline
\end{tabular}

${ }^{*}$ The + in the screening strategy refers to the diseases separately and as co-occurrence. Thus, LC + COPD refers to detecting patients with LC, or COPD, or LC and COPD

Note that the results may not appear to be exact, due to the rounding of the presented values

$M A C$ maximum acceptable cost, $L C$ lung cancer, $C V D$ cardiovascular disease, $C O P D$ chronic obstructive pulmonary disease, $Q A L Y$ qualityadjusted life-years, WTP willingness-to-pay 
Table 3 Headroom analysis outcomes for the smoking population of The Netherlands

Incremental disease management costs ( $€$ per screened individual)
Effectiveness gap (incremental

QALY per screened individual)
Incremental MAC $(€$ per screened individual)

WTP: €20 k/ WTP: QALY $€ 80 \mathrm{k} /$ QALY

Diseases screened* $\quad \begin{gathered}\text { Patients with } \\ \text { disease }\end{gathered}$

$\mathrm{LC}+\mathrm{CVD}+\mathrm{COPD}$

42,662

$-88$

0.034

$\mathrm{LC}+\mathrm{CVD}$

35,001

$-87$

0.030

2,499

$\mathrm{LC}+\mathrm{COPD}$

25,630

$-105$

0.018

1,546

$\mathrm{LC}$

12,655

$-110$

0.012

${ }^{*}$ The + in the screening strategy refers to the diseases separately and as co-occurrence. Thus, LC + COPD refers to detecting patients with LC, or COPD, or LC and COPD

Note that the results may not appear to be exact, due to the rounding of the presented values

$M A C$ maximum acceptable cost, $L C$ lung cancer, $C V D$ cardiovascular disease, $C O P D$ chronic obstructive pulmonary disease, $Q A L Y$ qualityadjusted life-years, WTP willingness-to-pay

Table 4 Headroom analysis for individuals over 60 years of age in The Netherlands

\begin{tabular}{|c|c|c|c|c|c|}
\hline & & \multirow[b]{2}{*}{$\begin{array}{l}\text { Incremental disease management } \\
\text { costs ( } € \text { per screened individual) }\end{array}$} & \multirow[b]{2}{*}{$\begin{array}{l}\text { Effectiveness gap (incremental } \\
\text { QALY per screened individual) }\end{array}$} & \multicolumn{2}{|c|}{$\begin{array}{l}\text { Incremental MAC ( } € \text { per } \\
\text { screened individual) }\end{array}$} \\
\hline & & & & $\begin{array}{l}\text { WTP: } € 20 \mathrm{k} / \\
\text { QALY }\end{array}$ & $\begin{array}{l}\text { WTP: } \\
€ 80 \mathrm{k} / \\
\text { QALY }\end{array}$ \\
\hline Diseases screened* & $\begin{array}{l}\text { Patients with } \\
\text { disease }\end{array}$ & & & & \\
\hline $\mathrm{LC}+\mathrm{CVD}+\mathrm{COPD}$ & 220,366 & 23 & 0.055 & 1,082 & 4,399 \\
\hline $\mathrm{LC}+\mathrm{CVD}$ & 201,796 & 24 & 0.052 & 1,028 & 4,185 \\
\hline $\mathrm{LC}+\mathrm{COPD}$ & 37,316 & -17 & 0.006 & 138 & 502 \\
\hline LC & 8,822 & -19 & 0.002 & 58 & 175 \\
\hline
\end{tabular}

${ }^{*}$ The + in the screening strategy refers to the diseases separately and as co-occurrence. Thus, LC + COPD refers to detecting patients with LC, or COPD, or LC and COPD

Note that the results may not appear to be exact, due to the rounding of the presented values

$M A C$ maximum acceptable cost, $L C$ lung cancer, $C V D$ cardiovascular disease, $C O P D$ chronic obstructive pulmonary disease, $Q A L Y$ qualityadjusted life-years, WTP willingness-to-pay

\section{Discussion}

To our knowledge, this study is the first to apply a headroom analysis estimating the MAC for a screening program. The MAC refers to an (optimistic) estimate of the upper limit of the acceptable cost per screened individual.

For Big-3 combination screening to be potentially costeffective for a screening population of current and former smokers between ages 50 and 75, costs should be substantially less than $€ 971$ for a WTP of $€ 20 \mathrm{k} / \mathrm{QALY}$ and $€ 3,844$ for a WTP of $€ 80 \mathrm{k} / \mathrm{Q} A L Y$. For breast and cervical cancer screening, costs of $€ 420$ per screened individual have been estimated, after converting the currency and expressing costs in 2020 Euros based on the Dutch Consumer price index
[40]. These screening costs include screening and diagnostic services, patient support, case management, program management, data management, and other smaller costs. This reference cost of breast and cervical cancer screening puts the MAC of Big-3 screening into perspective and in a positive light.

If we can assume that Big-3 screening will incur costs comparable to those of breast and cervical cancer screening. Then, the estimated MAC of $€ 113$ for LC-only screening compared to no-screening with a WTP of €20k/QALY seems low compared to previously published studies that found LC screening to be cost-effective [4-8]. However, higher WTP thresholds ranging between $21-85 \mathrm{k} € / \mathrm{LYG}$ and $30-140 \mathrm{k} € / \mathrm{QALY}$ were applied [4-8], which is comparable 

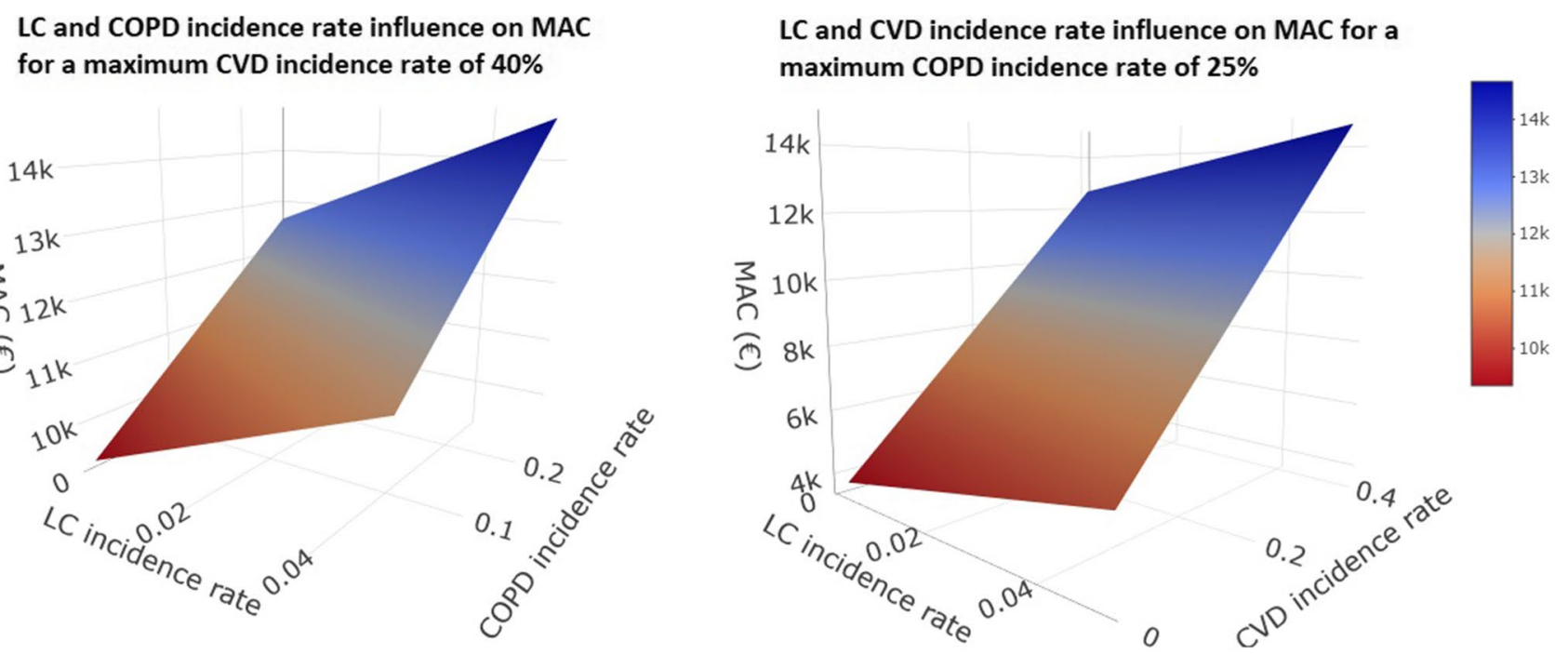

Fig. 2 The influence of COPD and CVD incidence rate on MAC. COPD, chronic obstructive pulmonary disease; CVD, cardiovascular disease; MAC, maximum acceptable cost

to the MAC of $€ 335$ per screened individual when evaluating LC screening at $€ 80 \mathrm{k} / \mathrm{QALY}$.

The results showed a higher MAC for screening for LC and CVD compared to LC and COPD, which can be ascribed to the limited benefits of early detection of COPD, where the most widely used treatment and only treatment in this model was smoking cessation, which is associated with poor adherence and which delays rather than avoids disease progression.

The MAC of Big-3 screening could be enlarged if a target screening population is identified with high disease incidences and, therefore, higher average health benefits per screened individual. In this study, the trade-off between a screening population with a high risk for one disease and a population with a relatively high disease risk for all of the Big-3 was illustrated. A focus on disease risk and subsequently, higher incidence rates, improves the cost-effectiveness of this combination screening program.

Further research is required to investigate the costeffectiveness of Big-3 screening based on prospective studies. These studies can, for instance, investigate an ideal target screening population and ideal recurrence of screening in a more in-depth analysis when evidence based on individual patient data for all three these diseases diagnosed with LDCT become available. To estimate the cost-effectiveness of Big-3 screening with more certainty, a comprehensive patient-level simulation model, populated with real-world data, would be required. In particular data such as participation rates, quality of life, and treatment outcomes of patients with co-occurrences are of importance. The adherence of individuals to screening within these target groups with high disease incidence rates might also be different when screening for different combinations of diseases.

This study had some limitations. First, the analysis assumed $100 \%$ sensitivity, specificity, and participation rate which is an unrealistic assumption but in the setting of this analysis provides an optimistic estimation which can be followed with a full cost-effectiveness analysis using real-world trial data. Second, for the base-case, all incidences in The Netherlands were assumed to occur within the defined screening population and detected in a single screening round of current and former smokers between 50 and 75 years of age which is intended to serve as a starting point for the evaluation of screening. Third, patients with co-occurrences are assumed to have the QALY (utility $\times$ survival) of the most severe disease. Fourth, incidence rates are used within the model, implying that a disease is only detected through screening within the first year of getting the disease; thereafter, the disease is always and automatically detected through current diagnostic processes. Fifth, the combination of three diseases into one screening program posed the challenge of identifying and synthesizing evidence into homogenous inputs and a simple model structure. It was challenging in this combination of diseases, where the nature of progression and curing of the Big-3 differ. Lastly, in this analysis, the impact of CVD events was based only on patients experiencing a myocardial infarction. Some of the assumptions are deliberately optimistic, which aligns with the goal of a headroom analysis, being an early-stage estimation of potential cost-effectiveness performed to filter out interventions that are certainly not cost-effective.

In conclusion, this study indicates that LDCT screening for LC, COPD, and CVD is likely more cost-effective than 
screening for LC only. The results suggest that the costeffectiveness of Big-3 screening can be further improved by optimising the target screening population to include individuals who are at risk, especially for CVD. These findings are of great relevance in the ongoing discussion about the cost-effectiveness of LC screening using LDCT. They warrant further research into expanding LC screening to combination screening for the Big-3, focusing on measuring the benefits of COPD and CVD screening using LDCT in future high-quality controlled studies.

Supplementary Information The online version contains supplementary material available at https://doi.org/10.1007/s00330-021-08422-7.

Acknowledgements We would like to thank S. Berghuis, D. Lingervelder and M. Kip for their valuable contributions in the early stages of the analysis.

Funding This project was partially funded by ZonMw (Dossier number: 10-10400-98-008). The funder had no role in study design, data collection and analysis, decision to publish, or preparation of the manuscript.

\section{Declarations}

Guarantor The scientific guarantor of this publication is Maarten IJzerman.

Conflict of interest Two authors of this manuscript declare relationships with the following companies:

$\mathrm{R}$. Vliegenthart is supported by an institutional research grant from Siemens Healthineers, by the Dutch Heart Foundation and The Netherlands Organisation for Health Research and Development.

In addition, M. IJzerman has held advisory board roles to Illumina and his institution (University of Melbourne) receives unrestricted research funding from Illumina.

Statistics and biometry No complex statistical methods were necessary for this paper.

Informed consent This study was not performed on human subjects, but only with aggregate, publicly available data.

Ethical approval Institutional Review Board approval was not required because the study only used publicly available data to inform further research.

\section{Methodology \\ - prospective \\ - early HTA \\ - multicenter study}

Open Access This article is licensed under a Creative Commons Attribution 4.0 International License, which permits use, sharing, adaptation, distribution and reproduction in any medium or format, as long as you give appropriate credit to the original author(s) and the source, provide a link to the Creative Commons licence, and indicate if changes were made. The images or other third party material in this article are included in the article's Creative Commons licence, unless indicated otherwise in a credit line to the material. If material is not included in the article's Creative Commons licence and your intended use is not permitted by statutory regulation or exceeds the permitted use, you will need to obtain permission directly from the copyright holder. To view a copy of this licence, visit http://creativecommons.org/licenses/by/4.0/.

\section{References}

1. Integraal kankercentrum Nederland (IKNL) (2017) Incidentie Longkanker. https://www.iknl.nl/kankersoorten/longkanker/regis tratie/incidentie. Accessed 12 Nov 2019

2. Louise C, Powell JT, Simon G, Sculpher MJ (2011) Reduced lungcancer mortality with low-dose computed tomographic screening. N Engl J Med 365:1863-1871

3. de Koning HJ, van der Aalst CM, de Jong PA et al (2020) Reduced lung-cancer mortality with volume CT screening in a randomized trial. N Engl J Med 382:503-513. https://doi.org/10.1056/NEJMo a1911793

4. Snowsill T, Yang H, Griffin E et al (2018) Low-dose computed tomography for lung cancer screening in high-risk populations: a systematic review and economic evaluation. Health Technol Assess 22:1-276. https://doi.org/10.3310/hta22690

5. Black WC, Gareen IF, Soneji SS et al (2014) Cost-effectiveness of CT screening in the National Lung Screening Trial. N Engl J Med 371:1793-1802. https://doi.org/10.1056/nejmoa1312547

6. Hofer F, Kauczor H-U, Stargardt T (2018) Cost-utility analysis of a potential lung cancer screening program for a high-risk population in Germany: a modelling approach. Lung Cancer 124:189198. https://doi.org/10.1016/j.lungcan.2018.07.036

7. Ten Haaf K, Tammemägi MC, Bondy SJ, et al (2017) Performance and Cost-effectiveness of computed tomography lung cancer screening scenarios in a population-based setting: a microsimulation modeling analysis in Ontario, Canada. PLoS Med 14:e1002225. https://doi.org/10.1371/journal.pmed.1002225

8. Tomonaga Y, ten Haaf K, Frauenfelder T et al (2018) Cost-effectiveness of low-dose CT screening for lung cancer in a European country with high prevalence of smoking - a modelling study. Lung Cancer 121:61-69. https://doi.org/10.1016/j.lungcan.2018. 05.008

9. Heuvelmans MA, Vonder M, Rook M et al (2019) Screening for early lung cancer, chronic obstructive pulmonary disease, and cardiovascular disease ( the Big-3) using low-dose chest computed tomography current evidence and technical considerations. Thorac Imaging 34:160-169. https://doi.org/10.1097/RTI.00000 00000000379

10. Bernheim A, Auffermann WF, Stillman AE (2017) The dubious value of coronary calcium scoring on lung cancer screening CT. J Am Coll Radiol 14:343-344. https://doi.org/10.1016/j.jacr.2016. 08.011

11. Labaki WW, Xia M, Murray S et al (2021) Quantitative emphysema on low-dose CT imaging of the chest and risk of lung cancer and airflow obstruction: an analysis of the National Lung Screening Trial. Chest 159:1812-1820. https://doi.org/10.1016/j.chest. 2020.12.004

12 Ruparel M, Quaife SL, Dickson JL et al (2019) Evaluation of cardiovascular risk in a lung cancer screening cohort. Thorax 74:1140LP - 1146. https://doi.org/10.1136/thora xjnl-2018-212812

13. Girling A, Lilford R, Cole A, Young T (2015) Headroom approach to device development: current and future directions. Int J Technol Assess Health Care 1:1-8. https://doi.org/10.1017/S026646231 5000501

14. Ijzerman MJ, Steuten LMG (2011) Early assessment of medical technologies to inform product development and market access a 
review of methods and applications. Appl Heal Econ Heal Policy 9:331-347

15. Girling A, Young T, Brown C, Lilford R (2010) Early-stage valuation of medical devices: the role of developmental uncertainty. Value Health 13:585-591. https://doi.org/10.1111/j.1524-4733. 2010.00726.x

16 Ijzerman MJ, Koffijberg H, Fenwick E, Krahn M (2017) Emerging use of early health technology assessment in medical product development: a scoping review of the literature. Pharmacoeconomics 35:727-740. https://doi.org/10.1007/s40273-017-0509-1

17. Griffin E, Hyde C, Long L et al (2020) Lung cancer screening by low-dose computed tomography: a cost-effectiveness analysis of alternative programmes in the UK using a newly developed natural history-based economic model. Diagnostic Progn Res 4:20. https://doi.org/10.1186/s41512-020-00087-y

18. De Koning H, Van Der Aalst C, Ten Haaf K, Oudkerk M (2018) PL02.05 effects of volume CT lung cancer screening: mortality results of the NELSON randomised-controlled population based trial. J Thorac Oncol 13:S185. https://doi.org/10.1016/j.jtho.2018. 08.012

19. Connor RJ, Chu KC, Smart CR (1989) Stage-shift cancer screening model. J Clin Epidemiol 42:1083-1095. https://doi.org/10. 1016/0895-4356(89)90050-4

20. Lloyd-Jones DM, Leip EP, Larson MG et al (2006) Prediction of lifetime risk for cardiovascular disease by risk factor burden at 50 years of age. Circulation 113:791-798. https://doi.org/10.1161/ CIRCULATIONAHA.105.548206

21. Hassett MJ, Uno H, Cronin AM et al (2017) Survival after recurrence of stage I-III breast, colorectal, or lung cancer. Cancer Epidemiol 49:186-194. https://doi.org/10.1016/j.canep.2017.07.001

22. Hoogendoorn M, Feenstra TL, Schermer TRJ, Hesselink AE, Rutten-van Mölken MPMH (2006) Severity distribution of chronic obstructive pulmonary disease (COPD) in Dutch general practice. Respir Med 100:83-86. https://doi.org/10.1016/j.rmed.2005.04. 004

23. Dai Y, Ge J (2012) Clinical use of aspirin in treatment and prevention of cardiovascular disease. Thrombosis 2012:245037. https:// doi.org/10.1155/2012/245037

24. Mohamed Hoesein FAA, Zanen P, de Jong PA et al (2013) Rate of progression of CT-quantified emphysema in male current and ex-smokers: a follow-up study. Respir Res 14:55. https://doi.org/ 10.1186/1465-9921-14-55

25. Carter BW, Lichtenberger JP, Benveniste MK et al (2018) Revisions to the TNM staging of lung cancer: rationale, significance, and clinical application. Radiographics 38:374-391. https://doi. org/10.1148/rg.2018170081

26. Shavelle RM, Paculdo DR, Kush SJ, Mannino DM, Strauss DJ (2009) Life expectancy and years of life lost in chronic obstructive pulmonary disease: findings from the NHANES III Follow-up Study. Int J COPD 4:137-148. https://doi.org/10.2147/copd.s5237

27 Løkke A, Lange P, Scharling H, Fabricius P, Vestbo J (2006) Developing COPD: a 25 year follow up study of the general population. Thorax 61:935LP - 939. https://doi.org/10.1136/thx.2006. 062802

28. van der Aalst CM, van den Bergh KAM, Willemsen MC, de Koning HJ, van Klaveren RJ (2010) Lung cancer screening and smoking abstinence: 2 year follow-up data from the Dutch-Belgian randomised controlled lung cancer screening trial. Thorax 65:600LP - 605. https://doi.org/10.1136/thx.2009.133751

29. McAteer H, Cosh E, Freeman G, Pandit A, Wood P, Lilford R (2007) Cost-effectiveness analysis at the development phase of a potential health technology: examples based on tissue engineering of bladder and urethra. J Tissue Eng Regen Med 1:343349. https://doi.org/10.1002/term.36

30. R Core Team (2018) R: A language and environment for statistical computing

31. Hoogendoorn M, Mölken MR, Hoogenveen R, Al M, Feenstra T (2010) Comparing the cost-effectiveness of a wide range of COPD interventions using a stochastic, dynamic, population model for COPD

32. Degeling K, Baxter NN, Emery J, et al (2020) An inverse stageshift model to estimate the excess mortality and health economic impact of delayed access to cancer services due to the COVID19 pandemic. medRxiv 2020.05.30.20117630. https://doi.org/10. 1101/2020.05.30.20117630

33. Greving JP, Buskens E, Koffijberg H, Algra A (2008) Cost-effectiveness of aspirin treatment in the primary prevention of cardiovascular disease events in subgroups based on age, gender, and varying cardiovascular risk. Circulation 117:2875-2883. https:// doi.org/10.1161/circulationaha.107.735340

34. Kievit W, Maurits JS, Arts EE, van Riel PL, Fransen J, Popa CD (2017) Cost-effectiveness of cardiovascular screening in patients with rheumatoid arthritis. Arthritis Care Res (Hoboken) 69:175182. https://doi.org/10.1002/acr.22929

35. Horeweg N, van der Aalst CM, Vliegenthart R et al (2013) Volumetric computed tomography screening for lung cancer: three rounds of the NELSON trial. Eur Respir J 42:1659LP - 1667. https://doi.org/10.1183/09031936.00197712

36. Maharani A, Sujarwoto, Praveen D, Oceandy D, Tampubolon G, Patel A (2019) Cardiovascular disease risk factor prevalence and estimated 10-year cardiovascular risk scores in Indonesia: the SMARThealth Extend study. PLoS One 14. https://doi.org/ 10.1371/journal.pone.0215219

37 Afonso ASM, Verhamme KMC, Sturkenboom MCJM, Brusselle GGO (2011) COPD in the general population: prevalence, incidence and survival. Respir Med 105:1872-1884. https://doi.org/ 10.1016/j.rmed.2011.06.012

38. CBS (2017) Bevolking; generatie, geslacht, leeftijd en herkomstgroepering. http://statline.cbs.nl/Statweb/publication/?DM= SLNL\&PA $=37325 \& \mathrm{D} 1=0 \& \mathrm{D} 2=0 \& \mathrm{D} 3=111-115 \& \mathrm{D} 4=0 \&$ $\mathrm{D} 5=0 \& \mathrm{D} 6=0,4,8,1 \& \mathrm{HDR}=\mathrm{T}, \mathrm{G} 3, \mathrm{G} 4, \mathrm{G} 5 \& \mathrm{STB}=\mathrm{G} 2, \mathrm{G} 1 \& \mathrm{VW}=\mathrm{T}$. Accessed 31 Aug 2017

39. CBS (2017) Leefstijl en (preventief) gezondheidsonderzoek; persoonskenmerken. http://statline.cbs.nl/statweb/publication/?vw= $\mathrm{t} \& \mathrm{dm}=\sin 1 \& \mathrm{pa}=83021 \mathrm{ned} \& \mathrm{~d} 1=0-16 \& \mathrm{~d} 2=0-2,5-13,37-41 \& \mathrm{~d} 3=$ $0 \& \mathrm{~d} 4=1 \& \mathrm{hd}=160208-1232 \& \mathrm{hdr}=\mathrm{g} 2, \mathrm{~g} 3, \mathrm{t} \& \mathrm{stb}=\mathrm{g} 1$. Accessed 31 Aug 2017

40. Ekwueme DU, Subramanian S, Trogdon JG et al (2014) Cost of services provided by the National Breast and Cervical Cancer Early Detection Program. Cancer 120(Suppl):2604-2611. https:// doi.org/10.1002/cncr.28816

Publisher's Note Springer Nature remains neutral with regard to jurisdictional claims in published maps and institutional affiliations. 